\title{
Exploring the Potential Relationships between Teaching Materials and Student Motivation
}

\author{
Koji Uenishi \\ Institute for Foreign Language Research and Education, Hiroshima University, Japan
}

\begin{abstract}
How to cite this paper: Koji Uenishi. (2019). Exploring the Potential Relationships between Teaching Materials and Student Motivation. The Educational Review, USA, 3(4), 34-42. http://dx.doi.org/10.26855/er.2019.04.001
\end{abstract}

*Corresponding author: Koji Uenishi, Institute for Foreign Language Research and Education, Hiroshima University, Japan.

Email: uenishi@hiroshima-u.ac.jp

\begin{abstract}
This paper investigates the potential usefulness of original teaching materials in order to enhance Japanese university students' intrinsic motivation when learning English including cross-cultural understanding, usefulness, and pleasure.Specifically, students who did not major in English language or education were taught English for one semester using the author's original textbook, based on his own various experiences overseas.Data analysis suggests thatalmost all students in the two classes examined enjoyed learning from the teaching materials, had a strong feeling of the importance of English learning, and had a strong awareness of developing English ability after studying each unit.
\end{abstract}

Keywords

Original teaching materials, Student motivation, Two-way ANOVAs

\section{Introduction}

This With regard to English learning in tertiary education, we educators and researchers need to continually evaluate our approach.University students who will use English as a tool in society after graduating from university need to improve their English proficiency, which might lead to theirincreased motivation to learn the target language at university.

In general, however, students lack motivation to learn English on a bachelor program, most of the students do not feel language learning to be meaningful or useful. Most student motivation relates to credit gains for their general English classes. Especially, by the time they become sophomores at university, students' attitudes toward English learningtend to become diverse. In fact, some students appear demotivated with regard to learning English and others are just losing interest in English. However, among sophomores some students have studied very seriously to obtain higher TOEIC Test scores or developing their English proficiency in order to studyabroad.

It appears vital for teachers to create a class to motivate English language students. In this paper, one effective method to promote this is considered, while teaching students who are less motivated or demotivated into English learning, in order to help them discover the significance of English study in class. An attempt is made to implant feelings of pleasure inEnglish learning and English usefulness into the studentsvia the use of original materials which might motivate students to learn the language.

\section{Earlier Research}

There have been a large number ofstudies on motivation in English learning.Particularattention has been paid to intrinsic motivation and extrinsic motivation. These two types of motivation are distinguished in self-determination theory (e.g., Deci \& Ryan, 1985; and, Ryan \& Deci, 2002). Intrinsic motivation is responsible for learners taking an interest in English learning and wanting to communicate with English speakers in English. Alternatively, extrinsic motivation,coming from external sources, leads to learners' positive attitudes towards taking qualifications or passing examinations (Deci \& Ryan, 1985). It is often said that such motivations do not conflict with each other, but form a diverse continuity (Lin, McKeachie, \& Kim, 2003).

Some research on intrinsic motivation has been conducted by introducing presentations into group activities in class. As a result, enhancement of intrinsic motivation has been shown to be successful (e.g., Tanaka \&Hiromori, 2007). Hayashi (2009) explores the relations of intrinsic and extrinsic motivations to learner activities by classifying English learners into three groups based on their autonomy, concluding that regardless of their autonomy, learners have a tendency towards 'enjoyable' activities in class. Iwanaka (2011) confirms that it might be possible to enhance learner motivations toward class activities, English classes and English learning by satisfying three psychological needs of 'competence', 'relatedness' and 'autonomy'. The above 
was conducted in order to enhance intrinsic motivation through various learner activities.

Miura (2010) conducted a seven-year longitudinal research on students' learning motivation from junior high school to university, and suggested that university students tend to feel less motivated with regard to language learning after entering university even though their motivation tended to increase at the third year of junior high and senior high schools.

Hamada's (2008) quantitative research on junior and senior high school students' awareness shows that course books were the strongest demotivator. Sakai and Kikuchi (2009) collected high school student learning motivation data and found three important motivation factors: learning contents and materials, lack of motivation, and test scores, especially for less motivated learners.

Tanaka (2009) conducted motivation research focusing on English learning materials, especially overseas dramas and movies, and then he found these to have the positive effect of enhancing intrinsic motivation. Use of DVDs has a great influence on student motivation for learning English.

Furthermore, enhancement of student motivation of English learning using movies in class has been attempted (e.g., Yoshimura, 2017; Fujiyama, 2015). For example, in Yoshimura's paper after understanding the outline of the story, students do the tasks (e.g., dictation and reading aloud) while watching part of the movies. As a result, it is reported that students were more motivated into English learning.

Uenishi (2016) used his original materials in class and administered the questionnaire on the students' awareness of English learning at the beginning and the end of the course. The results showthat the introduction of absorbing teaching content has had beneficial effects on university students at the high-beginner level, and that they are indeed motivated intrinsically into studying English.

Based upon his data results, Hamada (2011) liststhe followingeffective teaching methods in preventing demotivation:

(1) Practice listening by shadowing

(2) Communicative tasks

(3) Group/pair work

(4) Less use of grammar translation style

(5) Presentation

(6) Teacher's uniqueness

The last category, Teachers' uniqueness, covers teachers' creative ideas such astheir experiences abroad and their use of quizzes in English on current world news (Hamada, 2011). This category can be said to be related to the materials the teacher uses. When it comes to English reading classes especially, the teaching content has a crucially important effect on student learning motivation.

\section{Objectives}

The current research investigates university students' intrinsic motivation to learn English and explores the extent to which the content of teaching materials is receivedfavorably by non-English-major students, and the relationship between the teaching materials and student awareness of English learning. In particular, focusing on the four countries/areas introduced in class, learner affectivity about the content was compared and discussed. The specific research questions are:

(1) To what extent are teaching materials favored by students?

(2) Does learner awareness vary among teaching materials(amongstfour countries or regions)?

(3) How do students feel about the teaching materials?

\section{Methods}

The subjects were 83 students who were not majoring in English (non-English major students). Students were divided into several classes, based on TOEIC Test scores, and the classeswere taught using the author's original textbook, Ryu's Misadventures Abroad. Regarding the students' English levels, the average TOEIC scores of the Education and Combined faculties classeswere 389 (basic high level) and 486 (intermediate level) out of a maximum 990 points, respectively.

In the reading class, the author's textbook based upon overseas experiences was introduced to enhance student motivation into English learning. At the end of each unit a questionnaire was administered to explore learner awareness on the teaching materials and language learning. To obtain answers from the subjects, the questionnaire used a 6-point Likert scale. The questionnaire items were classified into four categories based upon the content of each questionnaire. Then, the collected datawere analyzed using Two-way ANOVAsand Pearson product-moment correlation. In the last item of the questionnaire the students were asked to freely describe impressive or interesting partsrelating to the teaching content.

\section{Class Content}

The research was designed to encourage students to take a greater interest in English learning, becoming more motivated to learn it, and enhancing their English proficiency through use of materials based on the teacher's traveling experiences, 
including 'misadventures'. The textbook introduced in classis the teacher's original, Ryu's Misadventures Abroad, which constitutes 24 chapters, covering eight countries or regions. However, as students have 15 classes in one semester, they could only cover 12 chapters (four countries or regions).Below are the nations or regions they read about, and some of the troubles or problems Ryu encountered.

China: The main character visits Beijing and appreciates Kyougeki (Chinese opera). He has a lot of difficulty understanding the content of it because it is explained in Chinese and the audience have to appreciate it looking at the English subtitle on the far-end screen. Also, he gives a presentation in English at the international conferencefor the first time, and is fatigued from reading his paper in front of an audience.After that, he goes back to his room at the hotel and gets ready for a bath.Then, he turns up the faucet in the bathroom to bathe. While waiting for the tub to be full of bath water, he starts to enjoy the TV. After a while he takes a nap with water running because of fatigue.As a result, he floods his hotel room with water and has to cope with the resultant problems.

Hawaii: The main character does the sightseeing on Oahu Island, such as pineapple fields and Waikiki Beach. He learns about history of the fields and he makes fun of his wife about her way of swimming. Also, at Pearl Harbor, one of the battlefields in World War II, he teaches his children about manners in places where there is a cenotaph on which the names of the war dead are engraved.Further, when climbing down the mountain on Oahu Island, the Diamond Head, he suffers from diarrhea and encourages himself to endure it, until he finally manages to get to the toilet at the foot of the mountain.

Sri Lanka: Before the civil war ends in the country, the main character visits the country to participate in an international conference. He looks at the severe situation of the strict security in the capital. On the city tour he knows the look of the city and the situation of the trains at Colombo Station in those days, and has a good time conversing with local people. Also, after the second day of the conference he joins the welcome party and enjoys eating and talking. However, he has food poisoning at night and suffers from diarrhea and vomiting. The next day he is dehydrated and taken to a hospital to see a doctor and he has to be in hospital.

Scotland: The main character goes to Edinburgh to attend a conference with other professors. He visits one of the professors who loves Japan and things Japanese, and he has a gorgeous dinner. When the conference starts, he is very moved to see one teacher practicing his presentation earnestly in the square. Also, he participates in the famous Tattoo Festival in Scotland and is overwhelmed by how big the festival is and how international and brilliant it is.

The following teaching methods were used in class.

(1) Vocabulary section (10 words)

(2) Reading the passages and checking phrases

(3) Listening Section: Listening and answering (4 questions)

(4) Listening to the teacher's explanation

(5) Reading comprehension (4 questions)

(6) Speaking Section: Filling intheblanks in two dialogues

(7) Doing role play using the above dialogues

Regarding the vocabulary section, students first check the meaning of each word or phrase. Then, they check not only the vocabulary in the section, but also difficult and unknown words and phrases in the handout the teacher prepared. Next, they read a slightly longer passage (800-1000 words). The passage comes with one or two photos in it, which hopefully can lower their resistance to reading the long text. If necessary, the teacher makes some comments on the photo(s) before reading.

With regard to the listening section in the passage, students listen to the $\mathrm{CD}$ and answer the questions. This type of longer text might be difficult for slow learners to read. Then, moving on to reading comprehension, students answer Japanese questions on the content of the passage in order to deeply understand it.Additional explanation based upon the writer's actual experiences further motivates learners to have a more positive attitude towards English learning.

In another activity, students fill in blanks in the dialogues created based on the text, and after checking answers, they play the roles of Ryu and another person from the text. There are two aims in the activity they should do. One aim of it is to deepen their understanding of the content while reading the passage again in order to fill in the blanks. The other aim is to enable them to have a 'virtual reality' experience of an overseas trip by doing the pair work activity as if they actually were Ryu traveling abroad.

The final section is a Speaking Section or a fill-in-the-blanks type in the conversation of the story. Based on the story content, the conversation between Ryu and Person A develops. In short, Regarding Ryu's overseas experience, Person A asks Ryu questions about it and Ryu answers the questions.

\section{Results and Discussion}

\subsection{Research Question (1)}

In this section RQ (1) “To what extent are the teaching materials favored by students?" is discussed. As for the responses to 
questionnaire items among all students, first several remarkableitems in the questionnaire are described.The mean scores of Item 5 (English will be useful in the future), Item 11 (Vocabulary section was effective) and Item 13 (Reading comprehension was effective) showed very high numerical values, 5.27, 5.08, and 5.04 on the 6-point Likert scale, respectively.Among the items, Items 11 and 13 belong to Category 4 (Effectiveness of questions) and these very high numerical values show how useful the questionsare to understand the texts, along with the other two ones (Items 12 and 14).

Also, the mean value of Item 6(I came to want to develop comprehensive English ability better) was very high, 4.95 . This means that many students had a strong awareness of developing English ability after finishing each unit. These results imply that the teaching materials including the writer's troubles while traveling abroad motivated them to learn English and urged them to understandthe textbookusing the questions, and that they feel how useful English is through the English classes.

To reiterate, the questionnaire items were classified into four categories based upon the content of each questionnaire (Table 3), and the relationship among the categories was analyzed using Pearson product-moment and discussed (see Table 5).

Reliabilities amongst the whole data were relatively high, since the range of Cronbach's Alpha was from .911 to .784. Therefore, for all the scales, reliability is considered acceptable. Table 4 shows that the mean scores of four categories are higher than 4.5 on the 6-point scale. This means that the teaching contents including questions on the texts are meaningful and useful for learner motivation and understanding the passages.

Table 1. Descriptive analysis

\begin{tabular}{ccccc}
\hline \multirow{2}{*}{ Class } & \multicolumn{3}{c}{ Statistics Items } \\
\cline { 2 - 5 } & Number & Mean & Standard Deviation & Standard Error \\
\hline Education & 38 & 4.793 & 0.683 & 0.055 \\
\hline Combined Faculties & 45 & 4.623 & 0.688 & 0.051 \\
\hline
\end{tabular}

Table 2. Total responses to questionnaire items (Mean scores)

\begin{tabular}{|c|c|c|c|c|c|c|c|c|c|c|c|c|c|c|}
\hline \multirow{2}{*}{ Mean } & \multicolumn{14}{|c|}{ Questionnaire Items } \\
\hline & 1 & 2 & 3 & 4 & 5 & 6 & 7 & 8 & 9 & 10 & 11 & 12 & 13 & 14 \\
\hline Mean Score & 4.53 & 4.77 & 4.37 & 4.42 & 5.27 & 4.95 & 4.67 & 4.79 & 3.99 & 4.68 & 5.08 & 4.67 & 5.04 & 4.66 \\
\hline
\end{tabular}

Table 3. Classification of Items

\begin{tabular}{lll}
\hline \multirow{2}{*}{ Category } & \multicolumn{2}{c}{ Classified items } \\
\cline { 2 - 3 } & Classification & Item \\
\hline Category 1 & Cross-cultural understanding & 1,2 \\
\hline Category 2 & Motivation into English learning & $3,4,6$ \\
\hline Category 3 & Pleasure of textbook content & $7,8,10$ \\
\hline Category 4 & Effectiveness of Questions & $11,12,13,14$ \\
\hline
\end{tabular}

Table 4. Descriptive analysis (Categories)

\begin{tabular}{lllll}
\hline \multirow{2}{*}{ Category } & \multicolumn{3}{c}{ Statistics Items } \\
\cline { 2 - 5 } & Number & Mean & Standard Deviation & Standard Error \\
\hline Category 1 & 83 & 4.649 & 0.614 & 0.067 \\
\hline Category 2 & 83 & 4.580 & 0.731 & 0.080 \\
\hline Category 3 & 83 & 4.714 & 0.781 & 0.086 \\
\hline Category 4 & 83 & 4.861 & 0.597 & 0.066 \\
\hline
\end{tabular}


Table 5. Correlative relationship (Total)

\begin{tabular}{lllll}
\hline \multirow{2}{*}{ Category } & \multicolumn{3}{c}{ Statistics Items } \\
\cline { 2 - 5 } & Number & Mean & Standard Deviation & Standard Error \\
\hline Category 1 & 1 & $0.514^{* *}$ & $0.710^{* *}$ & $0.362^{* *}$ \\
\hline Category 2 & 1 & $0.715^{* *}$ & $0.445^{* *}$ \\
\hline Category 3 & & & 1 & $0.424^{* *}$ \\
\hline Category 4 & & & \\
\hline$* *: p<.01$ & & &
\end{tabular}

Table 5 demonstrates thestrong correlation between Category 3 (Pleasure of textbook content) and two other categories: Category 1 (Motivation into English learning) andCategory 2 (Cross-cultural understanding). These results suggest that learner awareness of the enjoyment of reading the passages in the textbook relates totheir positive attitudes toward learning English and understanding of foreign cultures.In short, there is possibility that when the teacher provides students with interesting textbook or the enjoyable content and they enjoy learning English, they might deepen their understanding of the content and are motivated into English learning. In addition, there is a moderate correlation between Categories 1 and 2, indicating that understanding foreign cultures might relate to English learning motivation and thatany incorporation of foreign cultures including overseas experiences into class might influence student motivation.

\subsection{Research Question (2)}

In this section RQ (2) “Does learner awareness vary among teaching contents (four countries or regions)?” is discussed.

The two-way ANOVAs were conducted regarding learner awareness and classes, and the interactions betweenthem were identified $(F(3)=6.227, p<.001)$. In order to identify the differences among the groups, the data was analyzed using multiple comparison tests (Bonferroni). The results indicate significant differences between the two groups regarding Category 1 (Crosscultural understanding) and Category 3 (Pleasure of English learning), but there were no significant differences when it came to Category 2 (Motivation into English learning) and Category 4 (Effectiveness of questions). On the whole the higher mean scores of all categories show that learners tend to be highly motivated and enjoyed the teaching content. Nevertheless, students in the Faculty of Education understand foreign cultures more deeply and tend to learn English in a more enjoyable manner than those in the combined class.

The data were divided in terms of student English level or class, and analyzed using the two-way ANOVAs in order to identify any differences between countries in each category. As mentioned in the Research Methods, in general the classes in Liberal Arts Education were classified based upon students' TOEIC scores. The mean scores of Classes 1 and 2, were 381 points and 489 points, respectively.Class 1 belonged to the Faculty of Education, while Class 2 was the Combined class including the Faculties of Letters, Integrated Arts \& Sciences, Economics and Law.

Table 7 shows that all mean scores of categories tend to be very high. As for each category, the data obtained from the Education class was analyzed using the Multiple comparison test, Bonferroni. As a result, there were significant differences between China and Hawaii regarding Categories 1, 2, and 3 (Table 8). This shows that, compared to the teaching content, China, students understand foreign cultures of Hawaii more deeply and were much more motivated into English learning by the correspondent content.In addition, regarding the materials, Hawaii, the data results show the significant differences between Hawaii and Sri Lanka when it comes to Categories 1, 2, and 3, indicating that almost the same things as the above can be said between Hawaii and Sri Lanka.

Table 6. Descriptive analysis (Total)

\begin{tabular}{llcccc}
\hline \multirow{2}{*}{ Class } & \multicolumn{5}{c}{ Statistics Items } \\
\cline { 2 - 6 } & Category & Number & Mean & Standard Deviation & Standard Error \\
\hline Education & Category 1 & 38 & 4.813 & 0.579 & 0.094 \\
\hline Education & Category 2 & 38 & 4.564 & 0.798 & 0.129 \\
\hline Education & Category 3 & 38 & 4.945 & 0.734 & 0.119 \\
\hline Education & Category 4 & 38 & 4.850 & 0.557 & 0.090 \\
\hline Combined Faculties & Category 1 & 45 & 4.511 & 0.616 & 0.092 \\
\hline Combined Faculties & Category 2 & 45 & 4.594 & 0.678 & 0.101 \\
\hline Combined Faculties & Category 3 & 45 & 4.519 & 0.773 & 0.115 \\
\hline Combined Faculties & Category 4 & 45 & 4.869 & 0.635 & 0.095 \\
\hline
\end{tabular}


Table 7. Multiple comparison tests among categories (Total)

\begin{tabular}{llllclll}
\hline \multirow{2}{*}{ Category } & \multicolumn{7}{c}{ Statistics Items } \\
\cline { 2 - 7 } & Class 1 & Class 2 & Mean 1 & Mean 2 & $\begin{array}{l}\text { Standard } \\
\text { Error }\end{array}$ & F & $\mathrm{p}$ \\
\hline Category 1 & Education & $\begin{array}{l}\text { Combined } \\
\text { Faculties }\end{array}$ & 4.813 & 4.511 & 0.075 & 4.044 & 0.000 \\
\hline Category 2 & Education & $\begin{array}{l}\text { Combined } \\
\text { Faculties }\end{array}$ & 4.564 & 4.594 & 0.075 & 0.414 & n.s. \\
\hline Category 3 & Education & $\begin{array}{l}\text { Combined } \\
\text { Faculties }\end{array}$ & 4.945 & 4.519 & 0.075 & 5.724 & 0.000 \\
\hline Category 4 & Education & $\begin{array}{l}\text { Combined } \\
\text { Faculties }\end{array}$ & 4.850 & 4.869 & 0.075 & 0.256 & n.s. \\
\hline
\end{tabular}

Table 8. Multiple comparison tests (Education class)

\begin{tabular}{|c|c|c|c|c|c|c|c|}
\hline \multirow{2}{*}{ Category } & \multicolumn{7}{|c|}{ Statistics Items } \\
\hline & Class 1 & Class 2 & Mean 1 & Mean 2 & $\begin{array}{l}\text { Standard } \\
\text { Deviation }\end{array}$ & $\mathrm{F}$ & $\mathrm{p}$ \\
\hline \multirow[t]{6}{*}{ Category 1} & China & Hawaii & 4.566 & 5.026 & 0.092 & 4.998 & 0.000 \\
\hline & China & Sri Lanka & 4.566 & 4.737 & 0.092 & 1.856 & n.s. \\
\hline & China & Scotland & 4.566 & 4.921 & 0.092 & 3.855 & 0.001 \\
\hline & Hawaii & Sri Lanka & 5.026 & 4.737 & 0.092 & 3.141 & 0.011 \\
\hline & Hawaii & Scotland & 5.026 & 4.921 & 0.092 & 1.142 & n.s. \\
\hline & Sri Lanka & Scotland & 4.737 & 4.921 & 0.092 & 1.999 & n.s. \\
\hline \multirow[t]{6}{*}{ Category 2} & China & Hawaii & 4.421 & 4.746 & 0.092 & 3.522 & 0.003 \\
\hline & China & Sri Lanka & 4.421 & 4.421 & 0.092 & 9.646 & n.s. \\
\hline & China & Scotland & 4.421 & 4.667 & 0.092 & 2.666 & 0.048 \\
\hline & Hawaii & Sri Lanka & 4.746 & 4.421 & 0.092 & 3.522 & 0.003 \\
\hline & Hawaii & Scotland & 4.746 & 4.667 & 0.092 & 0.857 & n.s. \\
\hline & Sri Lanka & Scotland & 4.421 & 4.667 & 0.092 & 2.666 & 0.048 \\
\hline \multirow[t]{6}{*}{ Category 3} & China & Hawaii & 4.868 & 5.132 & 0.092 & 2.856 & 0.027 \\
\hline & China & Sri Lanka & 4.868 & 4.798 & 0.092 & 0.762 & n.s. \\
\hline & China & Scotland & 4.868 & 4.983 & 0.092 & 1.238 & n.s. \\
\hline & Hawaii & Sri Lanka & 5.132 & 4.798 & 0.092 & 3.617 & 0.002 \\
\hline & Hawaii & Scotland & 5.132 & 4.983 & 0.092 & 1.618 & n.s. \\
\hline & Sri Lanka & Scotland & 4.798 & 4.983 & 0.092 & 1.999 & n.s. \\
\hline \multirow[t]{6}{*}{ Category 4} & China & Hawaii & 4.678 & 4.875 & 0.092 & 2.142 & n.s. \\
\hline & China & Sri Lanka & 4.678 & 4.875 & 0.092 & 2.142 & n.s. \\
\hline & China & Scotland & 4.678 & 4.974 & 0.092 & 3.213 & 0.009 \\
\hline & Hawaii & Sri Lanka & 4.875 & 4.875 & 0.092 & 5.151 & n.s. \\
\hline & Hawaii & Scotland & 4.875 & 4.974 & 0.092 & 1.071 & n.s. \\
\hline & Sri Lanka & Scotland & 4.875 & 4.974 & 0.092 & 1.071 & n.s. \\
\hline
\end{tabular}


Table 9. Multiple comparison tests (Combined class)

\begin{tabular}{|c|c|c|c|c|c|c|c|}
\hline \multirow[b]{2}{*}{ Category } & \multicolumn{7}{|c|}{ Statistics Items } \\
\hline & Class 1 & Class 2 & Mean 1 & Mean 2 & $\begin{array}{c}\text { Standard } \\
\text { Deviation }\end{array}$ & $\mathrm{F}$ & $\mathrm{p}$ \\
\hline \multirow[t]{6}{*}{ Category 1} & China & Hawaii & 4.089 & 4.667 & 0.086 & 6.695 & 0.000 \\
\hline & China & Sri Lanka & 4.089 & 4.633 & 0.086 & 6.309 & 0.000 \\
\hline & China & Scotland & 4.089 & 4.656 & 0.086 & 6.566 & 0.000 \\
\hline & Hawaii & Sri Lanka & 4.667 & 4.633 & 0.086 & 0.386 & n.s. \\
\hline & Hawaii & Scotland & 4.667 & 4.656 & 0.086 & 0.129 & n.s. \\
\hline & Sri Lanka & Scotland & 4.633 & 4.656 & 0.086 & 0.258 & n.s. \\
\hline \multirow[t]{6}{*}{ Category 2} & China & Hawaii & 4.282 & 4.785 & 0.086 & 5.837 & 0.000 \\
\hline & China & Sri Lanka & 4.282 & 4.615 & 0.086 & 3.863 & 0.001 \\
\hline & China & Scotland & 4.282 & 4.696 & 0.086 & 4.807 & 0.000 \\
\hline & Hawaii & Sri Lanka & 4.785 & 4.615 & 0.086 & 1.974 & n.s. \\
\hline & Hawaii & Scotland & 4.785 & 4.696 & 0.086 & 1.030 & n.s. \\
\hline & Sri Lanka & Scotland & 4.615 & 4.696 & 0.086 & 0.944 & n.s. \\
\hline \multirow[t]{6}{*}{ Category 3} & China & Hawaii & 4.207 & 4.770 & 0.086 & 6.523 & 0.000 \\
\hline & China & Sri Lanka & 4.207 & 4.504 & 0.086 & 3.433 & 0.004 \\
\hline & China & Scotland & 4.207 & 4.593 & 0.086 & 4.463 & 0.000 \\
\hline & Hawaii & Sri Lanka & 4.770 & 4.504 & 0.086 & 3.090 & 0.013 \\
\hline & Hawaii & Scotland & 4.770 & 4.593 & 0.086 & 2.060 & n.s. \\
\hline & Sri Lanka & Scotland & 4.504 & 4.593 & 0.086 & 1.030 & n.s. \\
\hline \multirow[t]{6}{*}{ Category 4} & China & Hawaii & 4.717 & 4.994 & 0.086 & 3.219 & 0.008 \\
\hline & China & Sri Lanka & 4.717 & 4.894 & 0.086 & 2.060 & n.s. \\
\hline & China & Scotland & 4.717 & 4.872 & 0.086 & 1.803 & n.s. \\
\hline & Hawaii & Sri Lanka & 4.994 & 4.894 & 0.086 & 1.159 & n.s. \\
\hline & Hawaii & Scotland & 4.994 & 4.872 & 0.086 & 1.416 & n.s. \\
\hline & Sri Lanka & Scotland & 4.894 & 4.872 & 0.086 & 0.258 & n.s. \\
\hline
\end{tabular}

The mean scores of all categories in the Combined faculties class show the higher numerical values.As for each category, the Multiple comparison test, Bonferroni was conducted and the data was analyzed.As a result, since the numerical values of Categories in China regarding Category 1 through Category 3 were somewhat lower, there were significant differences between China and the other countries (Table 9). The data results indicate that, compared to the text content of China, students could deepen intercultural understanding of the other countries (Hawaii, Sri Lanka and Scotland) and be more attracted by the content of the more interesting stories.Also, it seems that this kind of learner awareness led to enhancement of learner motivation into further English study.Regarding Category 4 (Effectiveness of questions) related to text content, there was a significant difference only between China and Hawaii.As the data shown in Table 9 indicates, the mean score of Category 4 in China was very high and there was statistically no significant difference between China and the other two countries. This shows that students had a strong awareness of how effective the four types of questions were.

\subsection{Research Question (3): Free Description}

After learning each country/area, students were asked to freely describe their impressive or interesting parts etc. about the country/area.The main free comments collected after reading the story of each countrywere categorized and then they are shown in Tables10and11. 
Table 10. Free Description (Education class)

\begin{tabular}{llllll}
\hline \multirow{2}{*}{ Comments } & \multicolumn{4}{c}{ Country/Area } \\
\cline { 2 - 6 } & China & Hawaii & Sri Lanka & Britain & Average \\
\hline Understanding different culture & 11 & 22 & 17 & 18 & 17 \\
\hline Story of real experience/failure & 19 & 4 & 12 & 3 & 10 \\
\hline (The content) Interesting & 14 & 6 & 5 & 7 & 8.75 \\
\hline Want to go & 0 & 8 & 2 & 4 & 4.25 \\
\hline Enjoy reading/studying & 6 & 7 & 0 & 4.25 \\
\hline
\end{tabular}

When it comes to the total average number of each category, the comment described most was 'Understanding foreign culture'. In case of the Education class Table 10 shows that on the average 17 out of 38 students commented on it. In the Combined faculties class the average number was 17.25 out of 45 students (Table 11).It is considered that, through the units (four countries/ areas) they learned, they recognize they could know different things in those nations and broaden their minds in many respects.

The second most comment in the free description was that they are impressed with the story of the writer's actual experiences and failures.As for 'Story of real experience/failure', though the average numbers of the students writing the comment in Education and Combined facultieswere 9.5 and 9.75, respectively.However, in case of China the total number of students was 37 , overwhelmingly the large number among four countries.In short, the writer had a terrible and embarrassing experience of flooding the room with water at the hotel. While reading the passages, students might have felt as if it were their own affair and they probably thought it could happen to anybody as well. It is considered that the content of the story enthralled the students in class.

Also, regarding the third most comment, 'the content was interesting/a lot of fun', the total number of their comments on China was much larger (24 out of 83) than that of other nations.As mentioned above, it seems that it is related to the writer'sterrible experience and the students have been attracted by the writer's urgent situation in the story.Interesting enough, in both Education and Combined faculties classes, nobody answered that they want to go to China.As seen in the free comments, this result seems to have a strong relation with the bad image of China/Chinese people and environmental problems there.

Further, seven students in both classes are impressed that a hotel staffer in China was very kind and gentle when she appropriately coped with the problem the main character brought about at the hotel.In spite of their image, in the story the staffer was kind enough to talk to the guest and deal with it quickly without any complaints. Some of the students seem to have been amazed to know the big gap between their conception about the country and the real story they read in class.Also, in the story of Hawaii there were some students who wrote the following comments:

I felt as if I were really visiting the sightseeing spots in Hawaii because the story was full of realism.

It was easier for me to read the story because of the story was full of realism.

Ifelt closer to the story because it contained irony and jokes.

The content of the story in Hawaii moved students and there is possibility that it made them enjoy reading English and read English more. Regarding the story of Scotland, there were students who commented like this: I understood the on-the-spot situation clearly and felt as if I were traveling abroad while reading it. This comment gives the teacher more courage and motivation to teach English using this kind of content based on the true story containing actual experience. This shows how important the content is when we try to make students continue to study the target language. Furthermore, one student read the part of the story with the scenes where the professor jokes with other people and commented the following: I want to enjoy a conversation in English and become a speaker who can say some jokes in English.

Table 11. Free Description (Combined class)

\begin{tabular}{llllll}
\hline \multirow{2}{*}{ Comments } & \multicolumn{4}{c}{ Country/Area } \\
\cline { 2 - 6 } & China & Hawaii & Sri Lanka & Britain & Average \\
\hline Understanding different culture & 10 & 17 & 17 & 25 & 17.25 \\
\hline Story of real experience/failure & 18 & 6 & 13 & 2 & 5.75 \\
\hline (The content) Interesting & 10 & 7 & 1 & 12 & 5.75 \\
\hline Want to go & 0 & 13 & 3 & 2 & 3.25 \\
\hline Enjoy reading/studying & 1 & 7 & 1 & 5 \\
\hline
\end{tabular}




\section{Conclusion}

The teaching materials, including traveling abroad and encountering various kinds of trouble, were utilized in class andthe extent to which the teaching contents (the four countries/areas) favored by students and the relevancy between the teaching content and student motivation were explored. The current paper shows that actual experiences relate to enhancing motivation and it also evaluates the use of travel abroad materials, as mentioned in Uenishi (2016).

With regard to the data, while the mean scores of categories were high for both groups, in case of the Combined faculties class, the data shows that specific areas(i.e. Hawaii, Sri Lanka, and Scotland) were preferred,incomparison to the China text; conversely, for students in the Education class there were clear differences between the teaching contents, Hawaii and China/ Sri Lanka.In short, there appears to be a demonstration of preference for Hawaii to the other two countries.

The current paperwas conductedwith a relatively small cohort and limited number of subjects for a conclusive motivation study.Consideringa greater number offactors related to learner motivation, in addition to a richer variety of different textbooks and learner backgrounds would benefit additional investigations.

\section{References}

Cheung, C. (2001). The use of popular culture as a stimulusto motivate secondary students' English learning in Hong Kong. ELT Journal, 55 (1), 55-61

Deci, E. L., \& Ryan, R. M. (1985). Intrinsic motivation and self-determination in human behavior. New York: Plenum.

Fisher, H. E., Aron, A., \& Brown, L. L. (2006). Romantic Love: A Mammalian Brain System for Mate Choice. Philosophical Transactions ofthe Royal Society: Biological Sciences, 361, 2173-2186

Fujiyama, K. (2015). "Eiga wo katsuyoushitaeigogakushuu no doukizuke-kousendenotorikumi wo chuushinni [English learning motivation by use of movies-focusing on practice at technical college]," Hikaku Bunka Kenkyuu [Comparative Culture Journal], vol.117, 129-138

Hamada, Y. (2011). What demotivates and what prevents demotivation? Annual Research Report on General Education, Akita University, 13, 56-67

Hamada, Y. (2008). Demotivators for Japanese teenagers. Journal of PAAL, 12 (2), 1-23

Hayashi, H. (2009). Eigogakushuu no tanosisajuuyouseijikkounitsuitenogakushuushakannhikaku-doukiduke no kanntennkara [Enjoyment, importance, and execution of study activities in relation to learners' autonomy: Motivational perspectives]. Language education \& technology (46),191-212

Iwanaka, T. (2011).Gakushuuiyoku no koujounikoukensurukyoushitsukatsudou—kouryosubekimittsu no sinnritekiyokkyuu[Classroom activities contributing to enhancement of learning motivation-three psychological needs to consider-]. JACETCSCRB, Vol.8, 1-16

Kato, S. (2012). Eigogakushuugaeigogakushuusha no naihatsutekidoukidukeniataerueikyou no kennshou [Verification of effects of learning activities on English learners' intrinsic motivation]. Studies of Language and Culture,(6),9-22

Kato, S. (2008). Eigogakushuusha to doukizuuke: naihatsutekidoukizuke to gaihatsutekidoukizukekaranokousatsu [Engishlanguage learners and Motivation: Implications from intrinsic motivation and extrinsic motivation]. Kokusai keieibunkakennkyuu[International Business and Culture Research], 13(1), 57-65

Lin, Y. G., McKeachie, W. J., \& Kim, Y. C. (2003). College student intrinsic and/or extrinsic motivation and learning. Learning and Individual Differences, 13, 251-258

Miura, T. (2010). A retrospective survey of L2 learning motivational changes. JALT Journal, 32, 29-54

Ryan, R. M. \& Deci, E. L. (2002).Overview of Self-determination theory: An organismic dialectical perspective. In E. L. Deci and R. M. Ryan (Eds.), Handbook of Self-determination Research (pp.3-33). New York: University of Tochester Press.

Sakai, H.\& Kikuchi, K. (2009). An analysis of demotivators in the EFL classroom. System, 37, 57-69

Tanaka, H. (2009). Doukizukegahikuigakushuusha no doukizuke wo takamerujissenntekikenkyuu [Practical research to enhance low -motivated student motivation]. JACET Chugoku-Shikoku Chapter Research Bulletin, 6, 69-82

Tanaka, H., \&Hiromori, Y. (2007). Eigogakushuusha no naihatsutekidoukizuke wo takamerukyouikukainyuu to sonokouka no kennshou [Educational practical intervention to enhance English learners' intrinsic motivation and verification of the effects]. JALT Journal, 29, 59-80

Uenishi, K. (2016). Original teaching content and student motivation in the EFL Classroom. Hiroshima Studies in Language and Language Education, No.19, 65-81

Yoshimura, K. (2017). "Using movies as teaching materials to enhance student's motivation and encourage out-of-class study in junior college English education: a report of learning English conversation through movies," Bulletin of Kagoshima Women 's College, 53, 69-82 